\title{
APLICAÇÃO DE BIOADSORVENTE DE CASCA DE COCO VERDE PARA O TRATAMENTO DE EFLUENTES OLEOSOS
}

\author{
A. S. ALMAGRO ${ }^{1}$, S. M. S. ROCHA ${ }^{2}$ \\ ${ }^{1}$ Universidade Federal do Espírito Santo, Discente de Engenharia Química \\ ${ }^{2}$ Universidade Federal do Espírito Santo, Departamento de Educação e Ciências Humanas \\ E-mail para contato: albertoalmagro@hotmail.com
}

\begin{abstract}
RESUMO - A preocupação acerca de tratamento e reutilização de águas residuárias vem ganhando destaque na ciência, aumentando a importância de linhas de pesquisa nessa área, devido à preocupação com o meio ambiente. Porém, no que tange efluentes oleosos os tratamentos ditos convencionais não têm se mostrado eficazes na redução de óleos e graxas. Neste contexto a adsorção aparece como um tratamento alternativo para o tratamento destes efluentes. O carvão aditivado é o principal adsorvente comercial aplicado nas operações de adsorção. Apesar da alta eficiência, a aplicação de carvão ativado em larga escala é inviável devido o valor comercial desta substância. Assim, buscando viabilizar a utilização da operação de adsorção para o tratamento de efluentes oleosos, este trabalho objetiva encontrar adsorventes mais baratos que substituam o carvão ativado sem grandes perdas na eficiência de adsorção de óleos e graxas. Para a realização deste estudo, a fibra de coco verde foi escolhida como material adsorvente devido à sua abundância na região norte do estado do Espírito Santo, bem como por este material ser descartado de forma equivocada. De forma a se determinar o poder adsortivo das fibras, foram testadas diferentes variáveis de operação, tais como $\mathrm{pH}$, tempo de residência, concentração de adsorvente, temperatura do efluente e granulometria do adsorvente. Pode-se concluir que as fibras de coco possuem alto poder adsortivo, já que em todas as condições houve grande redução de óleo do efluente.
\end{abstract}

\section{INTRODUÇÃO}

A industrialização vem gerando cada vez mais infortúnios para o meio ambiente, prejudicando a saúde humana, principalmente. Dado que o tempo de degradação da maioria das substâncias poluentes descartadas na natureza é muito elevado, se faz necessário encontrar tratamentos que possam eliminar ou reduzir os impactos causados (Pereira, 2004).

Os corpos hídricos, portanto, merecem grande atenção no que se refere a estudos acerca de sua degradação, quer seja pelo descarte de efluentes ou pelo uso exagerado de água na produção. Durante séculos acreditou-se que a água era um bem inesgotável, a mudança neste status, trouxe preocupações para a ciência e toda a população, visto que praticamente todas as atividades humanas dependem de água. Dentre os principais poluentes dos recursos hídricos, pode se destacar os óleos e graxas, que são descartados através do efluente das mais vaiadas indústrias, seja porque utilizam substancias oleosas como matéria prima, ou devido ao uso de 
maquinários e manutenção dos mesmos. Grandes produtores de efluentes oleosos são os prestadores de serviços, tais como postos de gasolina e lava jato.

A adsorção consiste na adesão de moléculas em uma superfície adsorvente (Geankoplis, 1993 e Wang et al., 2007). Podendo ser influenciada pela temperatura, tempo de detenção hidráulica, $\mathrm{pH}$ do meio, concentração de adsorvente e granulometria do mesmo, esta interação se apresenta como uma potencial solução para o tratamento de efluentes. A busca por métodos de aplicação de baixo custo propõe o emprego de biomassa como uma alternativa ao tradicional e caro uso de carvão ativado (Mesquita et al., 2010), proporcionando também um nobre fim aos rejeitos agroindustriais.

\section{METODOLOGIA}

Para o desenvolvimento deste trabalho foi utilizado o efluente de um posto de combustível da cidade de São Mateus. De forma a se eliminar o óleo livre e demais impurezas presentes neste efluente, este foi submetido à sedimentação em cone Hinhoff para a decantação de partículas sólidas e separação água/óleo foi realizada em funil de separação tipo pera. O material bioadsorvente foi produzido através de fibras de coco lavadas e secas, que foram submetidas à operação de moagem em moinho de facas, as amostras trituradas foram separadas diferentes granulometrias, através de peneiração em peneiras entre os mesh 10 e 28 , ou seja, aberturas entre 1,7 e $0,6 \mathrm{~mm}$. Todos ensaios foram realizados em agitadores magnéticos, erlenmeyers de $250 \mathrm{~mL}$ e em triplicata, os testes foram realizados com $100 \mathrm{~mL}$ de efluentes e $0,1 \mathrm{~g}$ de adsorvente (excetuando o teste de concentração de adsorvente) e temperatura ambiente, exceto para o teste de temperatura, a cada variável posterior, os valores das variáveis ótimas determinadas eram fixadas. Os ensaios se deram conforme descritos por Macêdo (2013).

Teste de $\mathrm{pH}:$ De forma a se determinar o $\mathrm{pH}$ ótimo para a adsorção do óleo nas fibras de coco, ajustou-se o pH das amostras para os valores de 2, 4, 6, 8, 10 e 12 com o auxílio de soluções de $\mathrm{NaOH}$ (hidróxido de sódio) e $\mathrm{HCl}$ (ácido clorídrico) 0,05 mol/L, e estas amostras foram mantidas sob agitação constante durante 4 horas.

Teste de tempo: De forma a se determinar o tempo ótimo de adsorção as amostras de efluente com o $\mathrm{pH}$ corrigido para o valor ótimo $(\mathrm{pH}=2)$ foram submetidas à agitação constante durante o tempo de $10 \mathrm{~min}, 20 \mathrm{~min}, 1 \mathrm{~h}, 2 \mathrm{~h}, 3 \mathrm{~h}$ e $4 \mathrm{~h}$.

Teste de concentração de adsorvente: A concentração ótima de adsorvente foi determinada ajustando o $\mathrm{pH}$ das amostras para 2, adicionando se 0,1 g, 0,2 g, 1,0 g, 2,0 g, 3,0 $\mathrm{g}$ e 4,0 g de fibras de coco em cada amostra agitando durante o período de 1 hora (tempo ótimo de agitação)

Teste de temperatura: A temperatura ótima de adsorção foi determinada fixando-se o $\mathrm{pH}$, concentração de adsorvente e tempo de agitação previamente determinados e variando a temperatura em $25^{\circ} \mathrm{C}$ (ambiente), $40{ }^{\circ} \mathrm{C}, 50{ }^{\circ} \mathrm{C}, 60^{\circ} \mathrm{C}$ e $70{ }^{\circ} \mathrm{C}$.

Teste de granulometria: a granulometria ótima de adsorção foi determinada fixando todas as variáveis anteriores em seus valores ótimos e utilizando a massa de adsorvente ótima 
em diferentes granulometrias, as fibras retidas nas peneiras de mesh 10, 14, 20, 24, 28 e fundo.

O Teor de Óleos e Graxas (TOG) do efluente bruto e tratado foram determinados pelo método gravimétrico (refer). A extração foi realizada utilizando-se $25 \mathrm{~mL}$ de amostra em funil de separação do tipo pera, em que se adicionou $30 \mathrm{~mL}$ de hexano de forma fracionada. A fase orgânica foi recolhida em béqueres secos e tarados. O Hexano que foi coletado juntamente com a fase orgânica foi evaporado, sobrando no béquer apenas a fração de óleos e graxas presente na amostra. O TOG foi determinado a partir da Equação:

$$
\operatorname{TOG}(m g / L)=\frac{\left(m_{f}-m_{i}\right) 1000}{V(L)}
$$

\section{RESULTADOS E DISCUSSÃO}

De forma a se determinar o $\mathrm{pH}$ ótimo de adsorção do resíduo oleoso do efluente nas fibras de coco, foram realizados os testes conforme descrito na sessão 2, e os resultados estão apresentados na Figura 1.

Figura 1 - Influência do pH na adsorção.

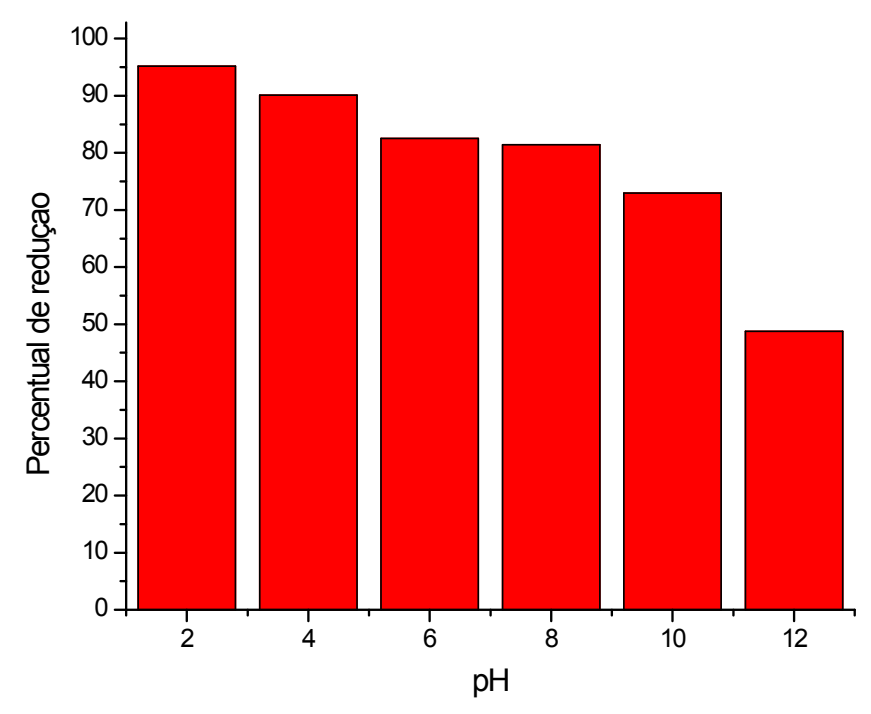

Nota-se que houve uma maior redução de teor de óleos e graxas nas amostras com $\mathrm{pH}$ ácido, visto que a literatura aconselha o $\mathrm{pH}$ ácido para a quebra de emulsões, pode se atribuir à esta quebra de emulsão o melhor resultado para o menor $\mathrm{pH}$ estudado $\mathrm{pH}=2$. Bem como também, pode ser devido à carga elétrica componente dos sítios ativos das fibras de coco. Assim, quanto menor o pH do meio, mais forte é a ligação do óleo no adsorvente. 
De forma a se determinar o tempo de detenção hidráulica do efluente, ou seja, o tempo que o efluente deve ficar em contato com o adsorvente para que ocorra a maior redução das frações de óleos e graxas, foram realizados testes de adsorção para diferentes tempos de contato. Os resultados referentes ao teste de tempo estão apresentados na Tabela 1.

Tabela 1 - Resultados obtidos através do teste de influência do tempo

\begin{tabular}{c|c|c}
\hline Tempo de ensaio $(\mathrm{min})$ & TOG $(\mathrm{mg} / \mathrm{L})$ & \% TOG \\
\hline 10 & $142 \pm 42$ & 80,00 \\
20 & $178 \pm 8$ & 74,93 \\
60 & $30 \pm 14$ & 95,77 \\
120 & $164 \pm 17$ & 76,90 \\
240 & $158 \pm 31$ & 77,75 \\
\hline
\end{tabular}

Nota-se que não há tendência linear quanto à influência no tempo de contato do efluente com o adsorvente. A análise dos resultados apresentados na Tabela 1 permite concluir que o melhor tempo de adsorção foi o de 60min. Dentro do desvio padrão dos resultados de 10 e 20 min pode observar que a fração residual de óleos e graxas presentes no efluente tratado é alta, este valor diminui consideravelmente para o tempo de 60 min e volta a aumentar para o tempo de 120 e $240 \mathrm{~min}$. Isso pode indicar que o adsorvente atinge um estado de saturação e posteriormente alcança o estágio de dessorção, ou seja, o óleo passa a retornar para o efluente.

Os resultados referentes à influência da concentração de adsorvente na operação de adsorção estão apresentados na Tabela 2.

Tabela 2 - Resultados obtidos através do teste de influência da concentração de adsorvente

\begin{tabular}{c|c|c}
\hline $\begin{array}{c}\text { Concentração de Adsorvente } \\
(\mathrm{g} / 100 \mathrm{~mL} \text { de efluente) }\end{array}$ & TOG $(\mathrm{mg} / \mathrm{L})$ & $\%$ TOG \\
\hline 0,1 & $174 \pm 31$ & 75,49 \\
0,2 & $134 \pm 20$ & 81,12 \\
1,0 & $160 \pm 28$ & 77,46 \\
2,0 & $262 \pm 37$ & 63,10 \\
3,0 & $182 \pm 14$ & 74,37 \\
5,0 & $180 \pm 28$ & 74,65 \\
\hline
\end{tabular}

A análise dos dados sugere que a concentração pouco influencia na adsorção. Apesar disso, a concentração de $0,2 \mathrm{~g}$ de adsorvente/100 mL de solução apresentou ligeira vantagem em relação às demais.

Na Figura 2, estão apresentados os resultados obtidos através do teste de influência da temperatura na adsorção da fração de óleos e graxas na fibra de coco. 
Figura 2 - Influência da temperatura na adsorção.

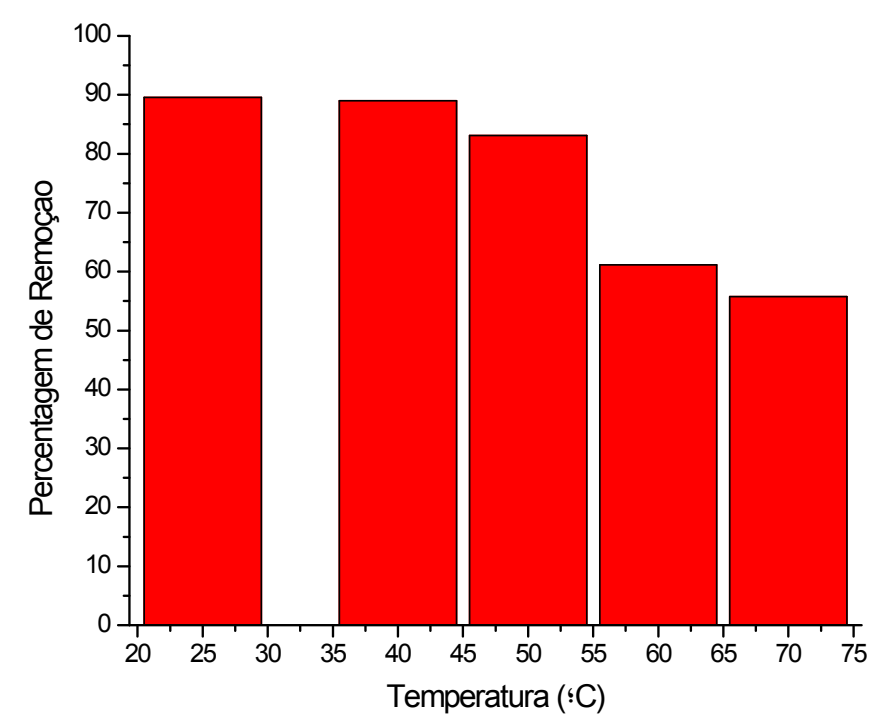

A análise dos dados sugere que o aumento da temperatura dificulta a adsorção. Isso provavelmente ocorre devido à natureza exotérmica da interação entre adsorvente e adsorvato. Além disso, nota-se que as amostras nas temperaturas ambiente (considerando $25^{\circ} \mathrm{C}$ ) e de 40 ${ }^{\circ} \mathrm{C}$ apresentam percentagem de remoção semelhantes. Considerando as necessidades de maior eficiência energética nos processos industriais, optou-se pela temperatura ambiente como a temperatura ótima para se dar sequência nos testes de adsorção.

Após se definir o melhor, $\mathrm{pH}$ de tratamento o tempo de detenção hidráulica a melhor temperatura de adsorção e a concentração de bioadsorvente a ser utilizada, foram realizados testes para determinar a influência da granulometria do material bioadsorvente na adsorção da fração de óleos e graxas na fibra de coco. A Tabela 3 representa os dados obtidos através do teste de influência da granulometria na adsorção de efluente oleoso utilizando fibras de coco.

Tabela 3 - Resultados obtidos através do teste de influência da granulometria

\begin{tabular}{c|c|c}
\hline Mesh Tyler & TOG $(\mathrm{mg} / \mathrm{L})$ & $\%$ TOG \\
\hline+10 & $350 \pm 8$ & 50,70 \\
$-14+20$ & $304 \pm 6$ & 57,18 \\
$-20+24$ & $256 \pm 28$ & 63,94 \\
$-24+28$ & $58 \pm 2,83$ & 91,83 \\
Fundo & $94 \pm 31$ & 86,76 \\
\hline
\end{tabular}


Os resultados apontam para uma eficiência maior quanto menor é a partícula. Isso era esperado, visto que quanto menor a partícula adsorvente, maior é a área de contato com o efluente, sendo maior a adsorção. Como essa maior área de contato expõe um maior número de sítios ativos, a adsorção é facilitada.

\section{CONCLUSÃO}

Os dados obtidos e a discussão realizada sugerem que as fibras de coco possuem alto poder adsortivo. O efluente oleoso pode, portanto, ser tratado utilizado esses rejeitos da indústria agrícola, reunindo duas soluções para problemas de descarte para o meio ambiente.

O método de ensaio por agitação mecânica em batelada apresentou resultados satisfatórios, sobretudo devido à sua simplicidade e alta reprodutibilidade. Desta forma a próxima etapa será a utilização de uma coluna de recheio para a realização de testes de forma continua.

\section{REFERÊNCIAS}

GEANKOPLIS, C. J., Transport Processes and Unit Operations. $3^{\mathrm{a}}$ Ed. Prentice-Hall Inc. Englewood Cliffs, New Jersey, 1993.

MACÊDO, J. A. B. D. Métodos Laboratoriais de Análises Físico-Químicas e Microbiológicas. 4ª Ed. Editora: CRQ-MG, 2013.

MESQUiTA, V. P. de, FILHO, C. J. S., MOTA, D. L. F., SEOLATTO, A. A., Avaliação da capacidade de adsorção de chumbo em casca de frutas comuns no cerrado brasileiro. XVIII Congresso Brasileiro de Engenharia Química, pág. 777-782, 2010.

PEREIRA, R. S., Identificação e caracterização das fontes de poluição em sistemas hídricos. Revista Eletrônica de Recursos Hídricos. IPH-UFRGS. V. 1, n.1. p. 20-36. 2004. http://www.abrh.org.br/informacoes/rerh.pdf

WANG, L. K., HUNG Y., SHAMMAS, N. K., Handbook of Environmental Engineering Advanced physicochemical treatment technologies. V.5, Human Press Inc. Totowa, New Jersey, 2007. 